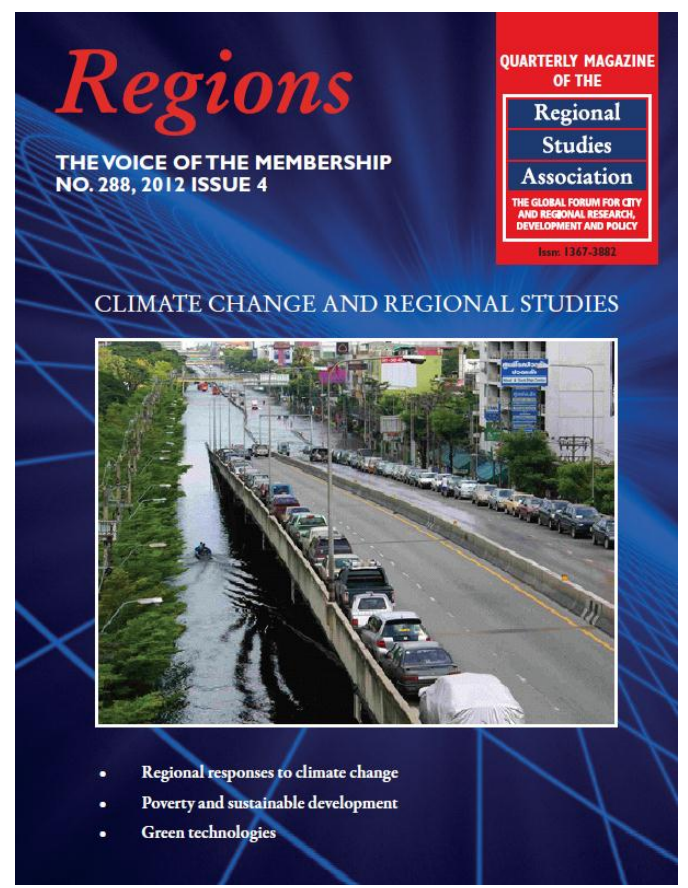

Esteves, L.S., 2012. Climate change adaptation in England: is managed realignment a sustainable strategy? Regions, 288(4), 16-18.

\title{
Climate change adaptation in England: is managed realignment a sustainable strategy?
}

\section{Luciana S. Esteves}

School of Applied Sciences, Bournemouth University, Poole BH12 5BB, UK lesteves@bournemouth.ac.uk

Adaptation can be defined as "adjustments in ecological-social-economic systems in response to actual or expected climatic stimuli, their effects or impacts" (Smit et al. 2000, p. 225). Adaption requires a change in behaviour (individual or collective) to increase resilience and sustainability. In 2005, Making Space for Water was implemented as the new strategy for managing flood and coastal erosion risk in England. It aims to "reduce the threat to people and their property" and "deliver the greatest environmental, social and economic benefits" following the principles of sustainable development (Defra 2005). Adaptation is a core driver for this strategy, having amongst its instruments the implementation of managed realignment (MR) as the preferred approach for managing flood risk in rural areas. This article discusses the sustainability of MR as a long-term adaptation strategy in England.

For centuries, engineering has controlled dynamic rivers and coasts to suit our socio-economic needs. As a result, a large number of people and assets are now located in hazard-prone zones and many natural habitats have been destroyed. Predictions of climate change in coastal areas worldwide include sea-level rise and more frequent and enhanced extreme weather events. Natural coasts can dynamically adjust to new conditions brought by climate change. However, this natural adaptation is hindered in coastlines 'fixed' by coastal defences and development, where rising sea levels and enhanced storms will increase flood and erosion risk (and the cost of protection) and affect intertidal habitats through coastal squeeze (Figure 1a). Underpinned by environmental concerns, MR represents a shift from the traditional 'hold-the-line' approach of coastal protection.

MR has been defined as "a process of establishing a new flood defence line for river corridors or coastlines, often set back from the existing position, with the aim of improving the long-term sustainability of the defence, or contributing to other aims such as habitat creation" (Defra 2005; $p$. 44). Although some authors use the terms MR and managed retreat interchangeably, there is a considerable difference in the approach represented by these terms. In the UK, MR most often refers to planned breaching of existing coastal defences and the construction of a new line of 
defences further inland to control flood risk (Figure 1b). Outside the UK, managed retreat usually describes the relocation of people and assets at risk (Figure 1c). Based on information provided in the ABPMer Online Managed Realignment Guide ${ }^{1}, 54$ MR projects involving artificial breaching of defences were undertaken in Western Europe, 29 of which in England. The oldest MR projects date from 1989 in Germany and the Netherlands and 1991 in England. The large majority of projects in England have multiple objectives: creation of intertidal habitats being the most common $(62 \%)$, followed by improvement of flood defences $(31 \%)$ and reduction of costs to maintain defences $(27 \%)$.

By allowing tidal waters to flow through breached defences, MR creates a new intertidal area (compare Figure 1a right with Figure $1 \mathrm{~b}$ left). As about $41 \%$ of the projects in England are within European designated conservation areas (i.e. Natura 2000 sites), it is anticipated that MR will provide compensation for intertidal habitat destruction (e.g. due to coastal squeeze), to meet statutory duty based on the EU Habitats Directive. The development of saltmarshes is a main objective, not only to compensate for the loss of these habitats but also because healthy saltmarshes provide a number of ecosystem services, such as natural protection against coastal erosion and flooding. Depending on a number of interacting physical and biological variables, including sediment availability, saltmarshes can accrete vertically, naturally adjusting to rising sea levels.

Information on the success of MR in re-creating saltmarshes is still scarce as the majority of projects do not benefit from long-term monitoring. The few existing studies indicate only limited achievements and a number of constraints. The MR at Freiston Shore (Lincolnshire), for example, is considered very successful due to the number of birds that now use the site. However, saltmarshes at the MR site developed at the expense of eroding adjacent natural habitats, negatively affected by the unexpected growth of the tidal channels created at the breaches (Rotman et al. 2008). Assessment of the functioning of re-created saltmarshes indicated they are "significantly impaired" when compared with natural systems, affecting "the delivery of ecosystem services including biodiversity, climate regulation and waste processing" (Spencer and Harvey 2012). Analysing 70 saltmarsh re-creation in Europe, Wolters et al. (2005) concluded that biodiversity increases at sites larger than 100 hectares and with the largest range of elevations between mean high water of neap and spring tides. Only $50 \%$ of the expected species were found in sites smaller than 30 hectares.

In England, $62 \%$ of the MR sites are smaller than 20 hectares and only $10 \%$ are larger than 100 hectares. Besides the small size, most sites are also low lying, limiting the establishment of species requiring higher elevations. These characteristics compromise the sustainability of MR sites, as the life-time of the newly created intertidal habitats will depend on whether sediment availability (and other variables) will allow vertical accretion at rates that will cope with rising sea levels. If saltmarshes are not able to fully develop, it is just a matter of time until water levels reach the new line of defences and the new intertidal habitats are again lost due to coastal squeeze (Figure 1b right).

Many MR projects are implemented in areas reclaimed from the sea hundreds of years ago. Some of these areas have developed into well-established habitats and are now designated areas of conservation. Implementation of MR in such areas will bring complex conflicts, not only between sectoral interests (e.g. nature conservation $v$. flood protection), but also in deciding which type of habitat is more valuable to be preserved. For example, Farlington Marshes (Portsmouth, southern England) were reclaimed in the 1770s and the presence of flood defences allowed the development of marshes and other freshwater habitats that are now within designated Natura 2000 sites. The plan for a local MR project faces strong opposition as it would affect a significant recreational space $(30,000$ visitors per year), destroy designated habitats supporting internationally important bird populations and affect flood risk to more than 500 homes and other assets (e.g. a major access road and the rail line). The EU Habitats Directive requires that losses of designated habitats are compensated by the creation of equivalent habitats. Here it leads to decide between

\footnotetext{
${ }^{1}$ http://www.abpmer.net/omreg/
} 
the uncertain gains brought by MR (which will depend on the type and quality of intertidal habitats that might develop) and the certain loss of realised and treasured values (which cannot be recreated locally or in the short-term). These conflicts are experienced in many other European coastlines and are well described in the literature:

"We are then confronted by the contradictory situation of ecosystem destruction and reestablishment both featuring prominently in society's agenda. The challenge is to manage the processes of change so that we do not irretrievably lose assets difficult or impossible to replace" (Maltby 2006, p.93).

All MR projects in England have been implemented at sites where flood defences were in poor conditions; $48 \%$ of which now benefit from new defences further inland. Usually, no information is provided on the maintenance costs of defences before and after MR, so no clear conclusions can be made on whether projects have been effective in reducing the costs to maintain defences. The poor state of conservation of the original defences indicates that they were not regularly maintained. Therefore, it is possible to assume that MR actually increases the costs to maintain defences in the immediate to medium-term if compared to the low maintenance of original defences. There is also a lack of information on how MR projects affect flood risk to inland areas. In rural areas, new defences are usually built to provide protection against events with $0.5 \%$ annual probability of occurrence (i.e. 1 in 200 year return period). However, as sea level is rising, the level of protection offered might reduce with time, depending on how the evolution of the MR site (e.g. vegetation development and sediment accumulation) will affect local water levels.

It is important that we adapt to both climate variability and extremes (Smit et al. 2000). As seen from the impact of hurricane Katrina in Louisiana (USA) and the tsunami which devastated the northeast coast of Japan in 2010, defences fail to protect against events of magnitudes exceeding their designed level of protection. The only safe way of reducing risk from extreme events involves removing people and infrastructure from hazard areas (Figure 1c). It is never too early to think about managed retreat and be prepared for the future. In England, examples of managed retreat are rare (e.g. relocation of the Belle Toute Lighthouse $17 \mathrm{~m}$ landwards from the receding cliff at Beachy Head). However, a recent initiative suggests that managed retreat is slowly becoming a reality. The North Norfolk District Council was awarded a £3 million grant by the Coastal Change Pathfinder Programme ${ }^{2}$ to test adaptation approaches including relocation of houses and assets at risk and the required community support (Frew 2012).

In England, there has been a lack of evidence that MR is linked to a long-term strategic plan. Projects are not required to have continuous monitoring (compromising assessments of success and long-term evolution); assessment of costs and benefits are not comprehensive (usually lack non-market and ecosystem service valuation); there is a lack of effective public participation in decision-making; and poor funding mechanisms hinder the consistency of land acquisition and/or compensation strategies. Furthermore, mixed messages are sent to the public when intensive coastal protection works funded privately are permitted adjacent to the largest MR project in England to date (Medmerry, Sussex).

MR has a great potential as a long-term adaptation strategy. In particular, MR can provide space for the creation of intertidal habitats and address some of the issues relevant to EU directives (i.e. Floods, Habitats and Water Framework). However, there has been little evidence that this potential will be realised in England if projects continue to be implemented at limited scales and without a long-term plan that effectively reduce risk from both climate change and extreme events. A step forward into adaptation will seek a transition from the limited scope of managed realignment to the complex (but effective) realm of managed retreat. Such transition will require a major change in the status quo of the planning system. If we consider it unfair to have inherited problems created in the 'era' of engineered coastlines, we must be careful not to create another intergenerational legacy by short-sighted de-engineering efforts which might cause unintended and costly consequences.

\footnotetext{
${ }^{2}$ http://www.defra.gov.uk/environment/flooding/coastal-change-pathfinders/
} 


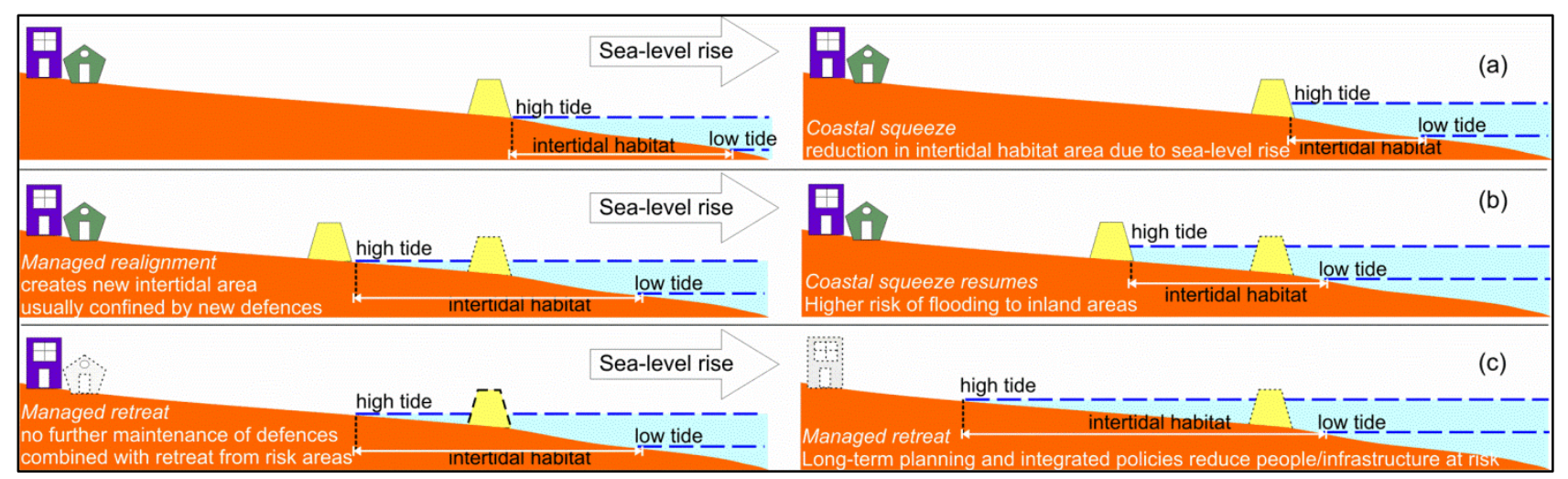

Figure 1. Coastal squeeze is the reduction in intertidal areas caused by rising sea levels along fixed coastlines (a). Managed realignment involves the creation of new intertidal areas by breaching existing defences and building a new line of defences further inland (b left). Due to rising sea levels, it might be only a question of time for the coastal squeeze to affect the newly created intertidal habitats ( $b$ right). Managed retreat involves a long-term planning to remove people and assets at risk, which will create space for the restoration of natural habitats.

\section{References}

DEFRA. 2005. Making space for water - Taking forward a new Government strategy for flood and coastal erosion risk management in England. First Government response to the autumn 2004 Making space for water consultation exercise. Department for Environment, Food and Rural Affairs, London.

Frew, P. 2012. Adapting to coastal change in north Norfolk, UK. Proceedings of the ICE - Maritime Engineering, 165(3), pages131-138.

Maltby, E. 2006. Wetland conservation and management: questions for science and society in applying the ecosystem approach. In: R. Bobbink; B. Beltman; J.T.A. Verhoeven and D.F. Whigham (Eds). Wetlands: Functioning, Biodiversity Conservation, and Restoration. Ecological Studies, 191(2), 93-116.

Rotman, R.; Naylor, L.; McDonnell, R. and MacNiocaill, C. 2008. Sediment transport on the Freiston Shore managed realignment site: An investigation using environmental magnetism. Geomorphology, 100(3-4), 241-255.

Smit, B.; Burton, I.; Klein, R.J.T. and Wandel, J. 2000. An anatomy of adaptation to climate change and variability. Climatic Change 45, 223-251.

Spencer, K.L. and Harvey, G.L. 2012. Understanding system disturbance and ecosystem services in restored saltmarshes: Integrating physical and biogeochemical processes. Estuarine, Coastal and Shelf Science 106, 23-32.

Wolters, M.; Garbutt, A. and Bakker, J.P. 2005. Salt-marsh restoration: evaluating the success of de-embankments in north-west Europe. Biological Conservation, 123(2), 249-268. 